\title{
Results of the First Phase of Educational Intervention in Schoolchil- dren of Marianao Municipality on Intestinal Parasitosis 2017-2019
}

\section{Osvaldo Batista Rojas, MSc*}

\author{
Municipal Unit of Hygiene and Epidemiology, Municpio Marianao, Cuba
}

*Corresponding author: Osvaldo Batista Rojas, MSc, Professor and Assistant Researcher, Municipal Unit of Hygiene and Epidemiology, Municpio Marianao, Havana, Cuba, Tel: +5356790289, +5372652681

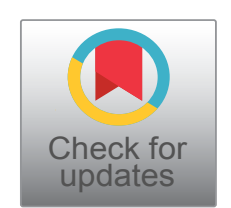

\begin{abstract}
An intervention study was carried out, quasi-experimental, retro-prospective with the students of the Primary School "Hugo Camejo" and their parents in the period 2017-2019. The universe was constituted by 627 students and the sample by the 83 schoolchildren of $4^{\text {th }}$ grade, with the objective of developing an intervention strategy to increase the level of knowledge about intestinal parasitosis. Reaching the following conclusions: Only half of the children before the intervention had adequate hygienic habits. The majority of the respondents have an average level of knowledge about parasitism before the intervention. The level of hygiene of the dwellings before the intervention. An educational intervention was designed. Almost all of the patients had a salutogenic behavior, which demonstrates the effectiveness of the intervention
\end{abstract}

\section{Keywords}

Schoolchildren, Epidemiology, Sanitary hygienic habits, Knowledge

\section{Introduction}

Prevalence rates in children throughout the world have not changed much in recent decades, despite the fact that effective therapeutic resources have increased and that many countries have established control programs for intestinal parasites [1,2].

In many cases the infection is asymptomatic, the most common symptoms are mainly gastrointestinal: Acute or chronic diarrhea, abdominal pain, anal itching, intestinal obstruction and deficiency: Anemia, weight loss and malnutrition. Bruxism, fever, cough, vulvovaginitis, insomnia, anorexia and dermatitis may also occur [3].
The enteroparasitosis despite having a worldwide distribution, is more common in tropical and subtropical areas of underdeveloped countries. The infant population is the most susceptible due to its immunological immaturity and the little development of hygienic habits. They are currently considered markers of underdevelopment by the United Nations [4].

The prevention and control of intestinal parasitosis is based not only on the knowledge of the biological cycle, the mechanisms of transmission and the natural history of the parasitic infection, but also on the study of the hygienic culture, beliefs and social organization. The benefits that are generated with their control, in addition to health, are observed in the social and economic sphere. The community is the scenario where preventive actions and promotion of health must be developed. These aspects are achieved by simple instructions at home, work, the environment, with the purpose of changing the behavior of the individual $[5,6]$.

Preventive actions are aimed at avoiding the appearance of parasitism or treating patients already ill in a timely manner, always with a public health vision. Among the complications of parasitism we have anemia, recurrent abdominal pain, chronic diarrhea, malnutrition, constipation, colic, intestinal obstruction as well as surgical emergencies such as acute appendicitis $[5,6]$.

To this end, timely diagnosis of parasitic diseases and the implementation of a series of activities with social and community participation and integrating all

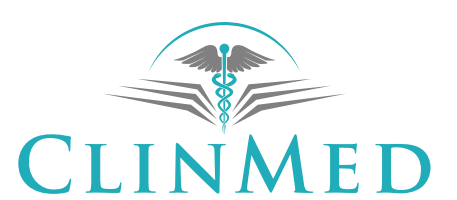

INTERNATIONAL LIBRARY

Citation: Rojas OB (2019) Results of the First Phase of Educational Intervention in Schoolchildren of Marianao Municipality on Intestinal Parasitosis 2017-2019. Int J Trop Dis 2:024. doi.org/10.23937/2643461X/1710024

Accepted: August 29, 2019; Published: August 31, 2019

Copyright: (C) 2019 Rojas OB. This is an open-access article distributed under the terms of the Creative Commons Attribution License, which permits unrestricted use, distribution, and reproduction in any medium, provided the original author and source are credited. 
sectors of this population will be very important $[5,6]$.

\section{- Scientific question}

How to increase the level of knowledge about intestinal parasites in the school "Hugo Camejo"?

\section{- Scientific problem}

Knowledge about intestinal parasitism in schoolchildren of the primary school "Hugo Camejo".

\section{- Hypothesis}

The knowledge about intestinal parasitism in the children of the primary school "Hugo Camejo" can be enriched with an educational intervention with the help of the community and therefore contribute to the decrease of intestinal parasitism.

\section{- Justification}

It is the first study to be carried out in the area, related to the prevention and intervention of intestinal parasites, contributing to the lower occurrence of these diseases, also achieving the intersectoriality of the Primary School with the other factors of the community, providing feasible tools for increase the level of knowledge of schoolchildren in said school and therefore decrease morbidity due to this pathology and reduce antiparasitic treatments if community intervention is correctly applied, as well as the appropriation of knowledge that leads to favorable changes in school health.

Having as objectives To develop a strategy of educational intervention to increase the level of knowledge about intestinal parasites in the primary schoolchildren "Hugo Camejo", Determine the hygienic habits of children and the level of knowledge about parasitism. Know the environmental hygienic level of the population under study. Design and implement a community intervention to improve the health of the community. Evaluate the effectiveness of the strategy.

\section{Material and Methods}

An intervention study was conducted, quasi-experimental, retro-prospective on the level of knowledge of schoolchildren and their parents about Intestinal Parasitism at the Primary School "Hugo Camejo" in the period 2017-2019 to increase knowledge about parasitism intestinal.

The universe of study was made up of the total number of students enrolled in the Primary School "Hugo Camejo" of Marianao Municipality, where 627 children from $1^{\text {st }}$ to $6^{\text {th }}$ grade study. The sample was constituted by the 83 students who attend the $4^{\text {th }}$ grade.

The inclusion and exclusion criteria of the study were applied to them to obtain the study sample in a non-probabilistic manner by criteria.

All $4^{\text {th }}$ graders are 83.

\section{Inclusion criteria}

The consent of the tutor will be taken into account.

\section{Exclusion criteria}

Tutors who refuse to participate in it will be excluded from the study. A survey made by the researcher was applied which was submitted to validation and perfected according to changes and criteria of experts.

\section{Intervention strategy}

The development of this intervention was divided into three stages:

Stage I: Level of knowledge: Once the children and their parents or representatives were selected, two questionnaires were applied, related to the level of knowledge and behaviors about intestinal parasitism, (Annexes I, II, III), for children and for parents, (Annex IV).

Stage II: Intervention itself: In a second moment the educational intervention was designed taking into account the existing gaps in knowledge about the disease and from a comprehensive bibliography review, this program responds to the growing need in the population to raise knowledge about intestinal parasitism allowing a greater community participation in the identification and eradication of the main difficulties within the community that favor the presentation and transmission of the disease.

Then proceeded to the actual intervention stage, which was carried out through educational activities based on a pre-established program, which will ensure that everyone participates actively in talks and participatory techniques where different topics related to the prevention of intestinal parasitism will be taught. These activities will take place over 11 months.

To exit Goal 4, the effectiveness of the intervention that will correspond to the last phase of the intervention will be evaluated.

In the last meeting will proceed to apply the questionnaire of research on knowledge and behavior in relation to parasitism (Annex II).

Stage III: Evaluation: Application of the questionnaires.

\section{Processing of information}

With the information collected, a spreadsheet was created in the Excel program to obtain the frequency distribution of the different variables and establish the comparisons. The processed data were presented in tables and graphs for better analysis and understanding, the verification or not of the statistical significance of the associations found, describing the corresponding absolute and percentage frequencies and applying the confidence intervals for the proportions when necessary. with a level of certainty of $95 \%$.

We apply the Likert Scale, (Annex File) for the preparation and evaluation of the questionnaires. 
Table 1: Hygienic habits of children before the intervention and after the intervention according to the parents' survey.

\begin{tabular}{|c|c|c|c|c|c|c|c|c|c|c|c|c|}
\hline \multirow{3}{*}{ Hygienic Habits } & \multicolumn{6}{|c|}{ Before Intervention } & \multicolumn{6}{|c|}{ After Intervention } \\
\hline & \multicolumn{2}{|c|}{ Adequate } & \multicolumn{2}{|c|}{$\begin{array}{l}\text { Adequate } \\
\text { Unsuitable }\end{array}$} & \multicolumn{2}{|c|}{ Unsuitable } & \multicolumn{2}{|c|}{ Adequate } & \multicolumn{2}{|c|}{$\begin{array}{l}\text { Adequate } \\
\text { Unsuitable }\end{array}$} & \multicolumn{2}{|c|}{ Unsuitable } \\
\hline & Number & $\%$ & Number & $\%$ & Number & $\%$ & Number & $\%$ & Number & $\%$ & Number & $\%$ \\
\hline $\begin{array}{l}\text { Wash hands before } \\
\text { eating food }\end{array}$ & 29 & 34.9 & 38 & 45.8 & 16 & 19.3 & 78 & 94.0 & 7 & 8.4 & 0 & 0 \\
\hline $\begin{array}{l}\text { Washing of hands after } \\
\text { defecation }\end{array}$ & 28 & 33.7 & 35 & 42.2 & 20 & 24.1 & 82 & 98.8 & 1 & 1.2 & 0 & 0 \\
\hline To walk without shoes & 40 & 48.2 & 28 & 33.7 & 15 & 18.1 & 80 & 96.4 & 3 & 3.6 & 0 & 0 \\
\hline Play with earth & 60 & 72.3 & 19 & 22.9 & 5 & 6.0 & 83 & 100 & 0 & 0 & 0 & 0 \\
\hline Nail biting & 50 & 60.2 & 17 & 20.5 & 16 & 19.3 & 70 & 84.3 & 8 & 9.96 & 5 & 6.0 \\
\hline Use of baby mouse bottle & 41 & 49.7 & 2 & 2.4 & 0 & 0 & 83 & 100 & 0 & 0 & 0 & 0 \\
\hline $\begin{array}{l}\text { Difference of the } \\
\text { adequate level }\end{array}$ & \multicolumn{12}{|c|}{ Average score in \% after Intervention 95.6. } \\
\hline
\end{tabular}

Table 2: Hygienic level in the homes before and after the intervention.

\begin{tabular}{|c|c|c|c|c|c|c|c|c|c|c|c|c|}
\hline \multirow{3}{*}{$\begin{array}{l}\text { Hábitos } \\
\text { higiénicos }\end{array}$} & \multicolumn{6}{|c|}{ Before Intervention } & \multicolumn{6}{|c|}{ After Intervention } \\
\hline & \multicolumn{2}{|c|}{ Adequate } & \multicolumn{2}{|c|}{$\begin{array}{l}\text { Adequate } \\
\text { Unsuitable }\end{array}$} & \multicolumn{2}{|c|}{ Unsuitable } & \multicolumn{2}{|c|}{ Adequate } & \multicolumn{2}{|c|}{$\begin{array}{l}\text { Adequate } \\
\text { Unsuitable }\end{array}$} & \multicolumn{2}{|c|}{ Unsuitable } \\
\hline & Number & $\%$ & Number & $\%$ & Number & $\%$ & Number & $\%$ & Number & $\%$ & Number & $\%$ \\
\hline Water quality & 20 & 24.1 & 19 & 22.9 & 44 & 53.0 & 73 & 88.0 & 10 & 12.0 & 0 & 0 \\
\hline Liquid residuals & 56 & 91.6 & 20 & 24.1 & 7 & 8.4 & 76 & 96.4 & 3 & 3.6 & 0 & 0 \\
\hline Solid residues & 21 & 25.3 & 34 & 40.1 & 28 & 33.7 & 80 & 91.6 & 5 & 6.0 & 2 & 2.4 \\
\hline
\end{tabular}

Table 3: Behavior of the parents before and after the intervention referred to intestinal parasitism.

\begin{tabular}{|l|l|l|l|l|}
\hline \multirow{2}{*}{ Behavior } & \multicolumn{4}{|l|}{ Moment of Intervention } \\
\cline { 2 - 5 } & Before & After \\
\cline { 2 - 5 } & Number & $\%$ & Numbers & $\%$ \\
\hline Salutogenic & 50 & 60.2 & 79 & 95.2 \\
\hline Harmful & 33 & 39.8 & 4 & 4.8 \\
\hline Total & 83 & 100 & 83 & 100 \\
\hline
\end{tabular}

\section{Results}

We can see in the Table 1 the effectiveness of the work done in the children operated on, as there was a notable increase in proper hygienic habits since before the intervention they had $49.8 \%$, and after the intervention we obtained an average percentage of $95.6 \%$, leaving only the $6.0 \%$ inadequate for eating the nails, the rest of the aspects analyzed after the intervention did not have important values.

The difference in percentages is applied, obtaining a significant value in $95 \%$ of the cases.

Before the intervention, the appropriate hygienic level only represented $24.1 \%$ of the sample and averaged $22.9 \%$, an important percentage value if we take into account that this section refers to solid waste, that is, garbage located in uncovered containers and/ or around the dwelling, after the intervention it can be seen that $96.4 \%$ had an adequate hygienic level in terms of liquid waste, in terms of water quality $88 \%$ with an adequate level and with solid waste $91.6 \%$ (Table 2). After the intervention, we only had two cases of deficient level due to the conservation of solid waste in the dwelling or its surroundings.

The difference is evident Salutogenic behavior was in $62 \%$ of the parents, after the intervention this behavior was present in $95.2 \%$ of the parents surveyed (Table 3). The difference of percentages for independent samples was applied, obtaining a value well above $95 \%$ of the respondents.

\section{Discussion}

In our country the average knowledge of primary school students about intestinal parasitosis is high, since it is between 72 and $75 \%$ of our students, especially if we compare ourselves with other developing countries of our continent, such as Peru, Colombia and Venezuela where studies state that only between $27 \%$ and $32 \%$ know of this disorder, while in the United States and Europe this rises between 72 and $85 \%$ [7].

After the intervention, adequate knowledge of children rises to $30 \%$ according to other researches in our country and in Latin America to $20 \%$, with ours equal to that of the United States and Europe [6].

In Cuba, between 41 and $45 \%$ of the population boils drinking water and the rest does not, in Latin America and Africa, however, these figures decrease 
considerably up to 27 and $30 \%$, due to poor hygienic conditions. health services in developing countries, on the other hand in the United States and Europe people who drink boiled water rise to $58 \%$ [8].

As soon as the disposition of the liquid residuals is present in the Cuban homes in $72 \%$, nevertheless the use of the bottle and the bottle in these ages of 6 to 11 years is reduced to $11 \%$ approximately [9-11].

The behavior of parents in our country is mostly salutogenic for $60 \%$, somewhat higher is the United States and Europe for 71\%, while in America and Africa the figures decrease significantly to 51 and $47 \%$ respectively [12].

After the intervention, salutogenic behavior increases to more than $80 \%$, in developed countries to 83 or $88 \%$ and in Latin America and Africa to 65 and $62 \%$ respectively [13].

Concluding that More than half of the students belong to the male sex, there are no illiterates and most have pre-university or secondary level Basic completed and the most important symptoms were abdominal pain, anorexia and vomiting. Only half of the children before the intervention had adequate hygienic habits. The majority of the respondents have an average level of knowledge about parasitism before the intervention. The level of hygiene of the dwellings before the intervention An educational intervention was designed. Almost all of the patients had a salutogenic behavior, which demonstrates the effectiveness of the intervention.

\section{References}

1. Sotolongo $F(1982)$ Generalidades de parasitología. $\left(5^{\text {th }}\right.$ edn), Editorial Pueblo y Educacióz, La Habana, 12-19.

2. Kourí P, Basnuevo R, Sotolongo F (1977) Lecciones de parasitología médica y medicina tropical. En: Protozoología médica. Instituto Cubano del Libro, La Habana, 3-10.

3. Jarabo MT, García Morán NP, García Morán JI (2014) Prevalencia de parasitismo intestinal en una población escolar. Centro Salud Mota Cuervo.

4. Benenson AS (1997) Manual para el control de las enfermedades trasmisibles. (16 ${ }^{\text {th }}$ edn), Rev Esp Salud Pública, Washington, DC, 499-500.

5. Zaldiva Díaz SR (2013) Enteroparasitosis, indicadores antropométricos y requerimientos alimentarios en niños de una localidad rural del estado de Sao Paulo. Tesis doctorado, Universidad de Sao Paulo, Sao Paulo, 94-102.

6. Devera R, Finali M, Franceschi G, Gil S, Quintero O (2005) Elevada prevalencia de parasitosis intestinales en indígenas del Estado Delta Amacuro, Venezuela. Rev Biomed 16: 289-291.

7. Puerto Quintana C del (1989) Higiene del medio. Editorial Pueblo y Educación, La Habana, 77-96.

8. Devera RA, Niebla PG, Nastasi CJ, Velásquez AVJ, González MR (2000) Prevalencia de Trichuris trichiura y otros enteroparásitos en siete escuelas del área urbana de Ciudad Bolívar, Estado Bolívar, Venezuela. Saber 12: 41-47.

9. Cabello E (2014) Prevalencia de coccidios intestinales. Comunidad indígena San Antonio del Morichal, Municipio Autónomo Gran Sabana, Estado Bolívar. Tesis, Universidad de Oriente, Ciudad Bolívar.

10. Rey L (2011) Parasitologia. (3 ${ }^{\text {rd }}$ edn), Rio de Janeiro, Guanabara-Koogan.

11. Esteban JG, Flores A, Aguirre C, Strauss W, Angles R, et al. (1997) Presence of very high prevalence and intensity of infection with Fasciola hepatica among Aymara children from the Northern Bolivian Altiplano. Acta Trop 66: 1-14.

12. Miranda RA, Xavier FB, Menezes RC (1998) Parasitismo intestinal em uma aldeia indígena Parakanã, Sudeste do Estado do Pará, Brasil. Cad Saúde Pública 14: 507-511.

13. Chacín-Bonilla L, Sánchez-Chávez Y (2000) Intestinal parasitic infections with a special emphasis on Cryptosporidium, in Amerindians from Western Venezuela. Am J Trop Med Hyg 62: 347-352. 


\section{Annex File}

\section{Annex I: Informed Consent.}

\section{(Parents, Guardians and Representatives)}

Intestinal diseases caused by parasites affect about a third of the world's population. Those people who live in developing countries, particularly those of tropical climate, have the tendency to be the most affected, adding the adverse social and economic conditions in which they develop, a very vulnerable group are children, bringing symptoms that sometimes can be serious for infants. ।

Parent or guardian I give my disposition so that my son is included in the intervention study on knowledge of intestinal parasitism in children belonging to our community.

I know that my son's participation is absolutely voluntary, that he can leave the study without my rights being affected and that he will be able to get medical attention if he needs it in the popular doctor's office.

I consider it very important to carry out this study in our country because parasitosis is a disease that involves a risk for a significant number of people, especially children, and with the participation of my son, I will contribute to the control and prevention of them.

Volunteer Signature

\section{Annex II}

\section{Questionnaire for Questions to Know Level of Information on Intestinal Parasitism.}

Do you know what Intestinal Parasitism is?

Have you ever had intestinal parasites or do you know any of your friends who have ever been sick because of this? Then and with all the desire to help you to increase your knowledge about it, we show you a series of questions that you must answer with all sincerity, so that later, the area doctor can help you clarify all your questions.

Thank you very much for your cooperation.

1- What do you understand by Intestinal Parasitism and what are the types of Parasites you know? Mark the correct answers.

a) __ Disease that plants have.

b) _ Condition that can affect children and men who do not take good care of their health, and occurs within our digestive system (belly or belly), causing damage.

c) __ It never heals.

d) __ It is transmitted from one person to another.

e) _ Parasites are divided into: protozoa (microscopic, which can not be seen with the naked eye) and helminths (worms).

f) __ Not all parasites are seen in the stool (poop).

2- Which of these proposals do you think are the ones that favor the appearance of the disease? Select them.

a) _ Greeting other children who have the disease.

b) __ Eat without having washed your hands previously.

c) __ Fruits and vegetables that are eaten without washing them first.

d) __ Drink unboiled water.

e) __ Consume street foods that are not hygienically prepared.

f) __ For walking or playing barefoot.

g) __ Do not keep nails cut and clean.

h) __ Do poop outdoors.

i) __ Keep garbage uncovered. 
j) __ Eat meat that has not been sufficiently cooked.

k) _ Bathing in pools.

3- Mark with an $\mathrm{X}$ what you think a child or anyone could feel if he had parasites.

a) __ Pain and swelling of the stomach.

b) __ Diarrhea (sometimes bloody).

c) __ Constipation.

d) __ Itching in the anus (buttocks).

e) __ Presence of earthworms or worms in the poop.

f) __ Decay or fatigue.

g) _ Lack of appetite.

4- From the following statements, you must choose which ones help prevent or prevent the onset of the disease.

a) _ Play with dirt.

b) _ Wash hands thoroughly before handling, eating and after going to the bathroom.

c) __ Drink pure or boiled water.

d) __ Keep nails short and clean.

e) __ Do not poop outdoors.

f) __ Keep the garbage tanks covered.

g) __ Do not walk barefoot.

h) _ Covering kitchen utensils and food with clean tablecloths, to prevent flies from falling on them.

i) __ Cooking enough food, mainly meats.

j) __ Do not buy food or spare parts in street sales that we do not see with hygiene (clean).

k) _ Take water from the jet and do not keep your hands clean.

5- What do you think should be done to any patient with Intestinal Parasitism?

a) _ Maintain the usual diet.

b) _ Go to the Health Center, so that doctors and nurses can cure it.

c) __ Raise the hygiene and cleaning measures in the house, and with the sick child.

d) _ Separate the patient's eating vessels to prevent the disease from being transmitted to the rest of the family members.

e) __ Leave it in the house and give it home remedies without having been attended to before the doctor.

Score 30 points in total, ( 6 for each question, 1 for each subsection).

0- 10 Poor, 11 - 20 Average, 21 - 30 adequate.

Thank you very much for your cooperation.

\section{Annex III}

\section{Survey Applied to Parents, Guardians or Representatives.}

Survey on the behavior of intestinal parasitism in a supposedly healthy infant population.

For your child say:

1. Age ---------

2. Sex

3. Schooling: 


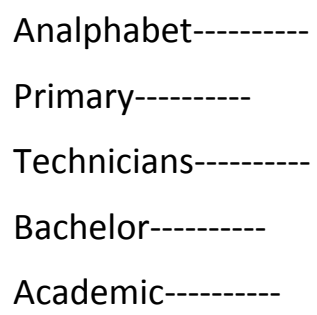

4. For which of these symptoms have you assisted the doctor with your child?

Abdominal pain

Anorexy

Diarrhea

Sickness

Vomiting

Urticaria

Constipation

5. Hygienic habits of the child.

5.1. Are you aware of washing the child's hands before eating?

a). Never:

b). Sometimes:

c). Forever:

5.2. Are you aware of the washing of the child's hands after defecation?

a). Never:

b). Sometimes:

c). Forever:

5.3. Do you allow me to walk barefoot?

a). Usually: b). Sometimes c). Never:

5.4. Do you play with dirt?

a). Yes:

b). Sometimes: c). Never:

5.5 Nail biting:

a). Yes:

b). Sometimes: c). Never:

6 . Conscious of the use of the bottle or bottle?

a). Always b). Sometimes c). Never

6. Hygiene in the home

6.1. Water quality:

a). Not boiled ------- b). Chlorinated ----- c). Boiled-----

6.2. Liquid residuals:

They keep liquid residuals inside the house

a). Usually ---- Occasionally ----- c). Never-----

6.3. Solid residuals:

a). Stores garbage in tanks without a lid

b) There is garbage around and patios

c) Stores garbage in tanks with lid

Qualification for items 5 and 6 . In all cases 1 point for subsection $a, 2$ points for subsection $b$ and 3 points for subsection c.

Total 45 points: up to 14 points deficient, 15 - 30 average and from 31 onwards adequate. 


\section{Annex IV}

Thematic Plan on Basic Themes for Students and Parents of the Primary School "Hugo Camejo" of The Municipality of Marianao.

\section{Thematic Plan:}

\begin{tabular}{|l|l|l|l|l|l|}
\hline \multirow{2}{*}{ No. } & & Hours by Type of Class & \multicolumn{2}{l|}{ TOTAL } \\
\cline { 3 - 5 } & TOPICS & Conferencies & Practical classes & Seminars \\
\hline 1 & Intestinal parasitism Concept and epidemiology & 4 & 2 & 2 & 8 \\
\hline 2 & Symptoms & 2 & 4 & 2 & 8 \\
\hline 3 & Most frequent parasites in children & 6 & 6 & 6 & 18 \\
\hline 4 & Prevention of Intestinal parasitism & 2 & 2 & 2 & 4 \\
\hline 5 & Pharmacotherapy & 2 & 2 & 12 & 4 \\
\hline Total & & 16 & 16 & 4 \\
\hline
\end{tabular}

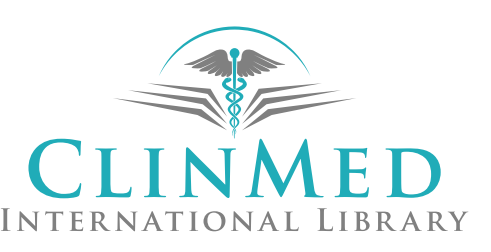

